\title{
Large-area homogeneous periodic surface structures generated on the surface of sputtered boron carbide thin films by femtosecond laser processing
}

\author{
R. Serra ${ }^{1}$, V. Oliveira ${ }^{2,3}$, J.C. Oliveira ${ }^{1}$, T. Kubart $^{4}$, R. Vilar ${ }^{3,5}$ and A. Cavaleiro ${ }^{1}$ \\ ${ }^{1}$ SEG-CEMUC, Mechanical Engineering Department, University of Coimbra, Rua Luís Reis Santos, \\ 3030-788 Coimbra, Portugal \\ ${ }^{2}$ ICEMS - Instituto de Ciência e Engenharia de Materiais e Superfícies, Avenida Rovisco Pais no 1, \\ 1049-001 Lisbon, Portugal \\ ${ }^{3}$ Instituto Superior de Engenharia de Lisboa, Avenida Conselheiro Emídio Navarro no 1, 1959-007 \\ Lisbon, Portugal \\ ${ }^{4}$ The Ångström Laboratory, Solid State Electronics, P.O. Box 534, SE-751 21 Uppsala, Sweden \\ ${ }^{5}$ Instituto Superior Técnico, Avenida Rovisco Pais no 1, 1049-001 Lisbon, Portugal
}

\begin{abstract}
Amorphous and crystalline sputtered boron carbide thin films have a very high hardness even surpassing that of bulk crystalline boron carbide $(\approx 41 \mathrm{GPa})$. However, magnetron sputtered B-C films have high friction coefficients (C.o.F) which limit their industrial application. Nanopatterning of materials surfaces has been proposed as a solution to decrease the C.o.F. The contact area of the nanopatterned surfaces is decreased due to the nanometre size of the asperities which results in a significant reduction of adhesion and friction. In the present work, the surface of amorphous and polycrystalline B-C thin films deposited by magnetron sputtering was nanopatterned using infrared femtosecond laser radiation. Successive parallel laser tracks $10 \mu \mathrm{m}$ apart were overlapped in order to obtain a processed area of about $3 \mathrm{~mm}^{2}$.

Sinusoidal-like undulations with the same spatial period as the laser tracks were formed on the surface of the amorphous boron carbide films after laser processing. The undulations amplitude increases with increasing laser fluence. The formation of undulations with a $10 \mu \mathrm{m}$ period was also observed on the surface of the crystalline boron carbide film processed with a pulse energy of $72 \mu \mathrm{J}$. The amplitude of the undulations is about 10 times higher than in the amorphous films processed at the same pulse energy due to the higher roughness of the films and consequent increase in laser radiation absorption.

LIPSS formation on the surface of the films was achieved for the three B-C films under study. However, LIPSS are formed under different circumstances. Processing of the amorphous films at low fluence $(72 \mu \mathrm{J})$ results in LIPSS formation only on localized spots on the film surface. LIPPS formation on the top of the undulations formed after laser processing
\end{abstract}


with $78 \mu \mathrm{J}$ of the amorphous film deposited at $800^{\circ} \mathrm{C}$. Finally, large-area homogeneous LIPSS coverage of the boron carbide crystalline films surface was achieved within a large range of laser fluences although holes are also formed at higher laser fluences.

Keywords: Surface nanostructuring, boron carbide, Sputtering, Femtosecond laser, LIPSS

\section{Introduction}

Boron carbide is among the hardest $(\approx 41 \mathrm{GPa}$ ) and most abrasion-resistant materials at ambient temperature and is even harder than diamond at high temperature [1,2]. Besides light weight armour and thermoelectric energy conversion, boron carbide is also an excellent material for hard and wear-resistant tribological coatings [3]. Polycrystalline $\mathrm{B}_{4} \mathrm{C}$ is only obtained when highly energetic deposition techniques are used [4]. Most of the work on the deposition of boron carbide by sputtering resulted in the deposition of amorphous B-C films. As a result, annealing of the as-deposited films at high temperature is necessary to crystallize the boron carbide structure [5,6]. Nevertheless, the as-deposited amorphous B-C films where shown to have very interesting mechanical properties with reported hardness even surpassing that of bulk crystalline boron carbide [7,8]. However, magnetron sputtered B-C films have high friction coefficients (C.o.F) which limit their industrial application [3,9]. Several authors attempt to decrease the C.o.F of amorphous boron carbide films by using hydrocarbons in the sputtering discharge $[5,6]$. Although the C.o.F of the deposited films was substantially decreased by incorporating higher amounts of carbon in the films, the results were obtained at the expenses of film hardness which undermine the industrial application of the films.

Nanopatterning of materials surfaces has been proposed as a solution to decrease the C.o.F [10-12]. The contact area of the nanopatterned surfaces is decreased due to the nanometre size of the asperities which results in a significant reduction of adhesion and friction. On the other hand, nanometre-sized asperities may be much harder than its corresponding bulk material due to their large surface area-to volume ratio, which will considerably enhance the wear resistance of a surface. In addition, the presence of nanopatterned asperities increases the surface hydrophobicity, which also leads to the reduction of adhesion and friction forces in a humid environment [9]. Several approaches have been proposed in the literature to achieve surface nanopatterning, such as UV, X-ray and scanning probe lithography, electron beam writing and focused ion beam milling, among others [13]. However these technologies are costly and have low flexibility and long processing times. In contrast, surface patterning using pulsed lasers beams is a powerful and versatile process for micro-machining and patterning of materials surfaces [14,15]. In particular, femtosecond lasers are promising tools for this purpose [16] since their extremely short pulse duration and very high peak power generate intense non-linear effects. As a result, almost any type of material can be processed, including transparent dielectrics, polymers and metals, without undesirable collateral thermal effects [17-20].

Irradiation of solid surfaces by femtosecond laser pulses produces regular surface structures with sub-micrometre spatial periodicity, frequently called laser-induced periodic surface 
structures (LIPSS). LIPSS are observed in a wide range of laser treated materials and their periodicity and orientation depend on the radiation wavelength, angle of incidence, and polarisation of the laser beam. Low spatial frequency LIPSS (LSFL) have a period of the same order of magnitude of the radiation wavelength (or slightly lower), while high spatial frequency LIPSS (HSFL) have periods of a few hundred nanometres. It has been shown in the literature that LFSL can be used to improve the tribological performance of thin solid films [21]. However, from an application point of view, large -area processing of the boron carbide films surface is mandatory. Processing of extended areas using femtosecond lasers has already been reported for other materials [22-24]. The aim of the present work is to produce large-area uniform femtosecond LIPSS on the surface of boron carbide thin films. For this purpose the influence of laser processing parameters on the formation of LIPSS on both polycrystalline and amorphous boron carbide thin films surface was studied.

\section{Experimental}

Boron carbide films (B-C) were deposited by magnetron sputtering from a hot-pressed polycrystalline $\mathrm{B}_{4} \mathrm{C}$ target with $99.95 \%$ purity in a pure argon atmosphere. The thickness of the as-deposited films was $600 \mathrm{~nm}$, as measured by scanning electron microscopy (SEM), regardless of the substrate deposition temperature. The ultimate vacuum pressure before deposition was lower than $5 \times 10^{-4} \mathrm{~Pa}$. Silicon substrates placed at $60 \mathrm{~mm}$ from the target were used in all depositions. The Si substrates were heated during the deposition process up to 200,800 and $1000{ }^{\circ} \mathrm{C}$. All experiments were carried out with a $450 \mathrm{~W}$ power applied to the $\mathrm{B}_{4} \mathrm{C}$ target and a deposition pressure close to $0.5 \mathrm{~Pa}$.

Femtosecond laser surface treatments of the boron carbide thin films were performed with a Yb:KYW chirped-pulse regenerative amplification laser system (Amplitude Systèmes s-Pulse HP) with a central wavelength of $1030 \mathrm{~nm}$ and a laser pulse duration of about $500 \mathrm{fs}$. The laser beam was focused by a $100 \mathrm{~mm}$ focal length lens and incident perpendicularly to the sample surface. The direction of its polarisation vector in relation to the beam scanning direction was controlled by a half-wave plate. The mean pulse energy was varied in the range 50 to $100 \mu \mathrm{J}$ by means of an attenuator in order to achieve average fluences at the surface of the sample ranging from 0.65 to $1.3 \mathrm{~J} / \mathrm{cm}^{2}$ at a pulse repetition rate of $10 \mathrm{kHz}$. Adjacent linear laser tracks approximately $100 \mu \mathrm{m}$ wide are produced by moving the B-C film substrates under the stationary laser beam using a computer-controlled $X Y Z$ stage with a scanning speed of $5 \mathrm{~mm} / \mathrm{s}$. In order to achieve complete surface coverage with $3 \mathrm{~mm}^{2}$ of treated area a lateral displacement of $10 \mu \mathrm{m}$ is applied between adjacent tracks by moving the stage in a direction perpendicular to the scanning direction.

The surface morphological details of the coatings were examined in a Philips XL30 scanning electron microscope (SEM) operated at $20 \mathrm{kV}$. Micro Raman spectroscopy was performed in HORIBA Jobin-Yvon Raman device with visible light source of $532 \mathrm{~nm}$ wavelength. The spectrum was measured in the range 240 to $2000 \mathrm{~cm}^{-1}$ with laser power of 20 to $25 \mathrm{~mW}$ for 30 seconds acquisition time. All measurements were performed at room temperature. White light interferometry was also used to characterize the surface topography in the thin films. The technique is able to image large sample areas with very high $\mathrm{z}$ resolution. 


\section{Results}

\subsection{As deposited films}

The surface of the as-deposited boron carbide films deposited at 200 and $800{ }^{\circ} \mathrm{C}$ is smooth and featureless (Figure 1a and b, respectively), much like the surface of the silicon substrates used in this work. In contrast, the surface of the film deposited at $1000{ }^{\circ} \mathrm{C}$ is heterogeneous and has a much higher roughness (Figure 1c). As can be observed from the higher magnification SEM image shown in Figure $1 \mathrm{~d}$, heating at $1000{ }^{\circ} \mathrm{C}$ resulted in the formation of well define grains with sharp edges and sizes up to about $100 \mathrm{~nm}$.

Figure 2 shows micro-Raman spectra of the as-deposited B-C thin films. Boron carbide has a complex structure consisting of icosahedral arrangements of twelve atoms at the vertices of a rhombohedral unit cell connected with three-atom chains along the main diagonal [25]. According to literature [26,27] the micro-Raman spectra of crystalline $\mathrm{B}_{4} \mathrm{C}$ has two narrow bands near $500 \mathrm{~cm}^{-1}$, associated to vibrations of the inter-icosahedral chains, and much wider peaks in the range from 600 to $1200 \mathrm{~cm}^{-1}$, associated to vibrations of the icosahedra. The micro-Raman spectrum of the B-C film deposited at $1000^{\circ} \mathrm{C}$ clearly shows these intense icosahedra related peaks with relative intensities corresponding to crystalline $\mathrm{B}_{4} \mathrm{C}$. The narrow bands associated with the inter-icosahedral chains may be masked by the intense Si substrate peak although a small intensity peak is detected near 480 $\mathrm{cm}^{-1}$. The micro-Raman spectra of the films deposited at 200 and $800{ }^{\circ} \mathrm{C}$ only show a very low intensity broad band in the range corresponding to the icosahedra vibrations (600 to $1200 \mathrm{~cm}^{-1}$ ) which is overlapped by background features. Both spectra are characteristic of amorphous boron carbide which consists of a disordered network of icosahedra.

\subsection{Laser processing of thin-films deposited at $200^{\circ} \mathrm{C}$}

Figure 3 shows SEM micrographs of the surface of films deposited at $200{ }^{\circ} \mathrm{C}$ after femtosecond laser irradiation with pulse energies between 65 and $78 \mu \mathrm{J}$. The surface of the film processed with $65 \mu \mathrm{J}$ is smooth and featureless much like the as-deposited surface (Figure 3a). A mostly smooth and featureless surface is also observed after processing with $72 \mu \mathrm{J}$ although with features dispersed on the film surface (Figure 3b). Observation of these features at higher magnification shows that they actually consist LIPSS perpendicular to the scanning direction with a spatial period of about $180 \mathrm{~nm}$ (Figure 3c). A further increase of the pulse energy up to $78 \mu \mathrm{J}$ (Figure $3 \mathrm{~d}$ ) leads to the complete removal of the film and to the formation of worm-like structures characteristic of silicon processed with femtosecond laser radiation [28].

The laser processed surfaces were also analysed by white light interferometry. Although the lateral resolution of this characterization method is too low to detect the formation of LIPSS, the vertical resolution allows observation of features with heights down to the nanometre. Figure 4 depict 3D images and 2D topographical profiles of the surface of the films processed with 65 and $72 \mu \mathrm{J}$. The presence of undulations parallel to the scanning direction 
with a period of about $10 \mu \mathrm{m}$ is clearly seen on both $3 \mathrm{D}$ images. The undulations amplitude is about $1.5 \mathrm{~nm}$ for the film processed with $72 \mu \mathrm{J}$, as can be readily concluded from the corresponding 2D topographical profile. Although the undulations are not clearly discernible in the 2D profile of the film processed with $65 \mu \mathrm{J}$, an amplitude of about $0.2 \mathrm{~nm}$ was found after mathematical processing to extract a sinusoidal signal.

Figure 5 displays micro-Raman spectra of the films treated with 65 and $72 \mu \mathrm{J}$. The microRaman spectra obtained over the treated surfaces show broad bands in the range from 600 to $1200 \mathrm{~cm}-1$ with low intensity and resolution, similar to those detected for the as-deposited amorphous film. As a result, the films remain amorphous even after laser processing and no structural transformation were detected. A micro-Raman spectrum was also acquired on the film treated with $78 \mu \mathrm{J}$ (not shown in Figure 5). In this case only Si and SiO2 were detected by spectroscopy confirming the complete film removal already observed by SEM.

\subsection{Laser processing of thin-films deposited at $800^{\circ} \mathrm{C}$}

Figure 6 depicts SEM micrographs of the surface of the B-C films deposited at $800{ }^{\circ} \mathrm{C}$ after irradiation with pulses energies between 65 and $85 \mu \mathrm{J}$. Once again the surface of the film laser processed at $65 \mu \mathrm{J}$ is smooth and featureless (Figure 6a), similar to the as-deposited surface. Increasing the pulse energy up to $72 \mu \mathrm{J}$ does not significantly change the film surface, although the formation of a few holes randomly dispersed on the surface film can be observed (Figure 6b). Note that LIPSS with a period of about $185 \mathrm{~nm}$ are formed on the border of the holes. At $78 \mu \mathrm{J}$ parallel stripes of LIPSS along the scanning direction are formed, separated by regions of unaltered film (Figure 6c). The distance between the stripes centre is about $10 \mu \mathrm{m}$ which corresponds to the overlapping distance between adjacent laser tracks. A close inspection shows that the LIPSS are perpendicular to the scanning direction with a period of $228 \mathrm{~nm}$. Finally, at $85 \mu \mathrm{J}$ the film is completely removed and the worm like structures characteristic of silicon processed with femtosecond laser radiation are formed (Figure 6d).

Figure 7 shows 3D images and 2D topographical profiles of the surface of the films laser processed with 72 and $78 \mu \mathrm{J}$. The presence of periodic undulations parallel to the direction of the laser tracks is clearly detected on both images. The period of the undulations is again the same as the laser tracks spacing $(10 \mu \mathrm{m})$. The $2 \mathrm{D}$ profile of the film processed with 72 $\mu \mathrm{J}$ shows sinusoidal-like undulations with an amplitude of about $1 \mathrm{~nm}$. The undulations formed after laser processing at $78 \mu \mathrm{J}$ are no longer sinusoidal-like, presenting a plateau-like shape on the top, and have a significantly higher amplitude (about $30 \mathrm{~nm}$ ) than in the previous case.

The micro-Raman spectrum of the surface of the B-C film processed with $72 \mu \mathrm{J}$ (Figure 8 ) is similar to the one obtain for the as-deposited film, showing that the amorphous as-deposited structure is not significantly changed. Although a mostly amorphous structure is still detected on the surface of the film processed at $78 \mu \mathrm{J}$, the intensity of the broad Raman bands between 600 and $1200 \mathrm{~cm}^{-1}$ is higher than in the as-deposited film (Figure 2 for $800{ }^{\circ} \mathrm{C}$ ). In this case, the characteristic shape of crystalline boron carbide Raman bands starts to emerge. At higher laser energies only $\mathrm{Si}$ and $\mathrm{SiO}_{2}$ are detected by micro-Raman 
spectroscopy, confirming the complete film removal already observed by SEM (not shown in Figure 8).

\subsection{Laser processing of thin-films deposited at $1000^{\circ} \mathrm{C}$}

SEM micrographs of the surface of the crystalline boron carbide film after laser processing are shown in Figure 9. Processing with laser fluences of 50 and $65 \mu \mathrm{J}$ resulted in complete homogeneous coverage of the film surface with LIPSS (Figure 9a and b). Complete coverage of the film surface with LIPSS is also achieved at $72 \mu \mathrm{J}$ although the formation of a few holes randomly dispersed on the film surface is also observed (Figure 9c). Increasing the laser fluence to $80 \mu \mathrm{J}$ significantly increases both the number and the size of the holes while the remaining film surface is still fully covered with LIPSS (Figure 9d). A further increase of the pulse energy up to $90 \mu \mathrm{J}$ leads to the complete film removal and formation of worm like structures (not shown). The spatial period of the LIPSS increases with the laser pulse energy, between 125 and $200 \mathrm{~nm}$, while their orientation is always perpendicular to the laser beam polarization.

Figure 10 shows 3D images and 2D topographical profiles of the surface of the crystalline boron carbide film processed with 65 and $72 \mu \mathrm{J}$. Both surfaces have a much higher roughness than the surface of the amorphous films processed with the same laser fluences. In both cases the film surface was laser ablated resulting in the formation of LIPSS which cannot be resolved by white light interferometry although originating a higher roughness. The formation of undulations, similar to the ones previously reported for the amorphous films, is also observed on the surface of the film processed at $72 \mu \mathrm{J}$. As LIPSS were simultaneously formed the undulations are much less defined than in the amorphous films. Nevertheless, an amplitude of $15 \mathrm{~nm}$ was estimated from the topographical graph (figure 10b). Although undulations may have been formed on the surface of the film processed at 65 $\mu \mathrm{J}$, their presence is completely masked by the LIPPS covering the entire film surface.

The micro-Raman spectra of films deposited at $1000^{\circ} \mathrm{C}$ and processed with 65 and $72 \mathrm{~mJ}$ pulse energy are shown in Figure 11. Well resolved and intense bands are present between 600 and $1200 \mathrm{~cm}^{-1}$ in both spectra showing that boron carbide remains crystalline after the laser processing. Two large bands centred near 1350 and $1600 \mathrm{~cm}^{-1}$ which are characteristic of an amorphous carbon phase also appear after laser processing. The intensity of these bands increases with increasing pulse energy showing that the quantity of amorphous carbon formed due to the laser treatment increases with the laser energy. For even higher laser energies (not shown) only $\mathrm{Si}$ and $\mathrm{SiO} 2$ are detected by micro Raman spectroscopy, showing that the film was stripped off the substrate.

\section{Discussion}

Sinusoidal-like undulations were formed on the surface of all the amorphous B-C films as a result of femtosecond laser processing. In all cases the period of the undulations corresponds to the spacing of the laser tracks $(10 \mu \mathrm{m})$. At low pulse energies the surface of the films is not significantly changed after laser processing, showing that the undulations do not result from laser ablation of the film surface. On the other hand, the structure of the surface after laser processing remains amorphous, as in the as-deposited state, which rules 
out phase transformations as a possible cause for the formation of the undulations. It is well known that amorphous boron carbide films deposited by magnetron sputtering have high residual compressive stresses dependent on the deposition conditions [29]. The residual stresses can be relaxed by annealing of the films [30]. In this work a Gaussian laser beam was used. The spatial fluence profile $F(r)$ is given by

$F(r)=\frac{2 E}{\pi w_{o}^{2}} e^{-\frac{r^{2}}{w_{0}^{2}}}$

where $\boldsymbol{E}$ is the pulse energy, $\boldsymbol{w}_{0}$ is the beam radius defined as the distance from the beam axis where the fluence drops to $1 / e^{2}$ of the peak value, and $r$ is the distance from the beam axis. The most probable explanation for the formation of undulations is that the laser radiation is thermalized within the $\mathrm{B}-\mathrm{C}$ films resulting in relaxation of the intrinsic compressive stresses. Since the laser intensity distribution is Gaussian, the temperature profile at the film surface is also Gaussian-like, resulting in more effective relaxation of the intrinsic compressive stresses near the centre of the laser beam. As a result, the stress relaxed regions will be under compression by the adjacent unaffected regions and local increase of the volume will occur.

The amplitude of the undulations formed after processing the amorphous B-C films at $72 \mu \mathrm{J}$ is lower for the film deposited with a higher substrate temperature (1 and $1.5 \mathrm{~nm}$, respectively). This results agrees well with the previous argument as heating of the B-C films during deposition decreases the compressive stresses which then results in lower volume increase after laser processing. On the other hand, the undulations amplitude increases with the laser fluence as should be expected from the compressive stresses relaxation mechanism due to the higher temperatures reached on the film surface.

The formation of undulations with a $10 \mu \mathrm{m}$ period was also observed on the surface of the crystalline boron carbide film processed with a pulse energy of $72 \mu \mathrm{J}$. Although lower residual stresses are to be expected in this film, as a result of the higher deposition temperature, the amplitude of the undulations is about 10 times higher than in the amorphous films processed at the same pulse energy. The surface of the crystalline boron carbide film has a much higher roughness than the surface of both amorphous films (see Figure 1). Since surface roughness enhances laser radiation abortion, the higher undulations amplitude results from the higher temperatures reached with the same laser fluence on the surface of the crystalline film.

The formation of LIPSS on the surface of the films was achieved for the three B-C films under study. However, LIPSS formation occurs under different circumstances. Processing of the amorphous films at low fluence $(72 \mu \mathrm{J})$ results in LIPSS formation only on localized spots on the film surface as shown in figure 3c. It is well known from the literature that LIPSS form at radiation fluences close to the material ablation threshold [16]. Since most of the B-C film surface is not ablated for this pulse energy, the generation of LIPSS is most probably due to the presence of surface defects which enhances laser radiation absorption and locally increases the effective radiation fluence above the films ablation threshold. This conclusion is supported by the evolution of the spots into holes with LIPSS on the border at higher fluences, as shown in Figure 6c. LIPPS formation was also obtained on the top of the 
undulations formed after laser processing with $78 \mu \mathrm{J}$ of the amorphous film deposited at 800 ${ }^{\circ} \mathrm{C}$ (Figures $6 \mathrm{~d}$ and $\mathrm{e}$ ). The top of the undulations correspond to the higher radiation fluences where the ablation threshold of the material is exceeded. Assuming that the beam radius $\mathrm{w}_{0}$ is equal to half the width of the laser track $(50 \mu \mathrm{m})$, the fluence threshold for LIPSS formation can be estimated to be about $2.0 \mathrm{~J} / \mathrm{cm}^{2}$. Complete removal of the film was observed after treatment at $85 \mu \mathrm{J}$ which correspond to a maximum radiation fluence of $2.2 \mathrm{~J} / \mathrm{cm}^{2}$. Finally, homogeneous LIPSS covering the entire processed surface were obtained after processing the crystalline boron carbide film with pulses energies above $50 \mu \mathrm{J}$. In this case the fluence threshold for LIPSS formation was estimated to be about $1.3 \mathrm{~J} / \mathrm{cm}^{2}$.

The spatial period of the LIPSS formed in this work ranges from 140 to $200 \mathrm{~nm}$ depending on the laser pulse energy, as shown in table 1. Upon irradiation of solids with linearly polarized femtosecond laser pulses in air under normal incidence, two distinct types of LIPSS are observed: LSFL and HSFL. LSFL have spatial periods close to the irradiation wavelength $\lambda$ while HSFL have spatial periods significantly smaller than the irradiation wavelength [31]. Since the wavelength of the laser radiation used in this work is $\lambda=1030$ $\mathrm{nm}$, the spatial period of the LIPSS generated in the B-C thin films surface is about 5 times smaller than the irradiation wavelength and all the observed LIPSS can be classified as HSFL.

In a recent study Chrakravarty and co-workers [32] compared the spatial period of LIPSS formed in semiconductors with different bandgaps. The authors showed that, under the same laser processing conditions, LSFL are observed in narrow bandgap semiconductors while HSFL are observed in wide bandgap semiconductors. These results were explained considering that LIPSS are formed due to the excitation of a surface plasmon wave at the semiconductor surface which interferes with the incident laser radiation. According to the authors, the critical factor in deciding the LIPSS spatial period is the electron density of the surface plasmon wave. LSFL are obtained for high plasma electron densities while HSFL are observed when the electron density approaches a minimum critical value for which the formation of LIPSS is no longer observed. Since the absorption of ultra-short laser pulses in materials with a narrow bandgap occurs through a combination of linear and non-linear absorption processes, a larger availability of free electrons in the conduction band is expected in these materials when compared with wide bandgap materials, where only nonlinear absorption processes can take place. As a result, a much lower surface plasma electron density is expected for wide bandgap semiconductors and, accordingly, the formation of HSFL is observed in these materials. In addition, the authors reported that the spatial period of the HSFL increases with increasing laser radiation fluence, an effect they explained by the dependence of the plasma electron density on the incident laser radiation intensity. The results reported in this work for the boron carbide films are consistent with this interpretation of LIPSS formation: i) as the estimated bandgap of boron carbide (1.64 eV [33]) is higher than the energy of the incident laser radiation used in this work (1.2 eV) boron carbide can be considered a wide bandgap semiconductor; ii) the spatial period of the HSFL observed in the boron carbide films increases with increasing pulse energies. Finally, it should be noted that the formation of LSFL was not observed in neither crystalline nor amorphous B-C films. It is well known from the literature that LSFL form at laser radiation fluences slightly higher than those required for HSFL [32]. In this work the films were 
completely removed from the substrate before reaching the radiation fluences for LSFL formation.

The fluence threshold for HSFL formation in the crystalline films $\left(1.3 \mathrm{~J} / \mathrm{cm}^{2}\right)$ is significantly lower than for the amorphous films $\left(2.0 \mathrm{~J} / \mathrm{cm}^{2}\right)$. Once again, this result is due to the higher surface roughness of the crystalline film which enhances laser radiation absorption. The crystalline film presents a lower threshold for HSFL formation because it absorbs more laser radiation than the amorphous films. This is consistent with the observation that for similar pulse energies, the spatial period of the LIPSS is smaller for the amorphous films. In addition, it is also well known from the literature that roughened surfaces lead to a more efficient excitation of surface plasmons [34] which in turn may contribute to facilitate the formation of LIPSS in the crystalline film at lower radiation fluences.

From the application point of view, laser processing of the crystalline boron carbide films seems to be more promising than processing of the amorphous films. Large-area homogeneous LIPSS coverage of the boron carbide crystalline films surface was achieved within a large range of laser fluences although holes are also formed at higher laser fluences. Furthermore, the spatial period of the LIPSS can be tune by changing the laser fluence. Although LIPPS formation was also observed on the surface of the amorphous films within a narrow window of laser fluences, complete homogeneous coverage was not achieved. However, the undulations formed on the surface of the amorphous boron carbide films may have a beneficial effect on the films coefficient of friction. Note that the amplitude of the undulations can be tune at the nanometre scale trough the laser fluence. Processing of the amorphous film deposited at $800^{\circ} \mathrm{C}$ with a laser fluence of $78 \mu \mathrm{J}$ promoted simultaneous formation of LIPSS (over most of the film surface) and undulations, resulting in a heterogeneous nanopatterned surface which may also reduce the friction coefficient.

\section{Conclusions}

Amorphous and polycrystalline boron carbide thin films deposited by magnetron sputtering were processed using infrared femtosecond laser radiation. Successive parallel laser tracks $10 \mu \mathrm{m}$ apart were overlapped in order to obtain a processed area of about $3 \mathrm{~mm}^{2}$.

Sinusoidal-like undulations with the same spatial period as the laser tracks were formed on the surface of the amorphous boron carbide films after laser processing. The most probable explanation for their formation is that the laser radiation is thermalized within the B-C films resulting in local relaxation of the intrinsic compressive stresses and consequent local volume increase. The undulations amplitude increases with increasing laser fluence. The formation of undulations with a $10 \mu \mathrm{m}$ period was also observed on the surface of the crystalline boron carbide film processed with a pulse energy of $72 \mu \mathrm{J}$. The amplitude of the undulations is about 10 times higher than in the amorphous films processed at the same pulse energy due to the higher roughness of the films and consequent increase in laser radiation absorption.

The formation of LIPSS on the surface of the films was achieved for the three B-C films under study. However, LIPSS formation occurs under different circumstances. Processing of the amorphous films at low fluence $(72 \mu \mathrm{J})$ results in LIPSS formation only on localized spots on the film surface. LIPPS formation on the top of the undulations formed after laser 
processing with $78 \mu \mathrm{J}$ of the amorphous film deposited at $800{ }^{\circ} \mathrm{C}$. The fluence threshold for LIPSS formation can be estimated to be about $2.0 \mathrm{~J} / \mathrm{cm}^{2}$. Finally, homogeneous LIPSS covering the entire processed surface were obtained after processing the crystalline boron carbide film with pulses energies above $50 \mu \mathrm{J}$. In this case the fluence threshold for LIPSS formation was estimated to be about $1.3 \mathrm{~J} / \mathrm{cm}^{2}$. The significant lower fluence threshold for LIPSS formation as compared to the amorphous films was also explained by the increased radiation absorption due to much higher surface roughness. The spatial period of the LIPSS increases with laser fluence from 140 to $200 \mathrm{~nm}$. In all cases the LIPSS spatial period is much lower than the laser wavelength showing that HSFL were formed.

From the application point of view, laser processing of the crystalline boron carbide films seems to be more promising than processing of the amorphous films. Large-area homogeneous LIPSS coverage of the boron carbide crystalline films surface was achieved within a large range of laser fluences although holes are also formed at higher laser fluences.

\section{Acknowledgments}

This research is sponsored by FEDER funds through the program COMPETE and by national funds through Portuguese Foundation for Science and Technology (FCT), under the project PEst-C/EME/UI0285/2013 and through the Grant SSFRH/BPD 17382712010.

\section{References}

1. J.C. Oliveira, O. Conde, Deposition of boron carbide by laser CVD: a comparison with thermodynamic predictions, Thin Solid Films 307 (1997) 29-37

2. O. Conde, A.J. Silvestre, J.C. Oliveira, Influence of carbon content on the crystallographic structure of boron carbide films, Surf. Coat. Techn. 125 (2000) 141-146

3. P. Larsson, N. Axen, S. Hogmark, Tribofilm formation on boron carbide in sliding wear, Wear 236 (1999) 73-80

4. C. Louro, J.C. Oliveira, M. Chhowalla, A. Cavaleiro, Silicon Effect on the Hardness of r.f. Sputtered B-C:Si Amorphous Films, Plasma Process. Polym. 6 (2009) S141-S145

5. H.-S. Ahn, P.D. Cuong, K.-H. Shin, Ki-Seung Lee, Tribological behavior of sputtered boron carbide coatings and the influence of processing gas, Wear 259 (2005) 807-813

6. T. Eckardt, K. Bewilogua, G. van der Kolk, T. Hurkmans, T. Trinh, W. Fleischer, Improving tribological properties of sputtered boron carbide coatings by process modifications, Surf. Coat. Techn. 126 (2000) 69-75

7. Z. Han, G. Li, J. Tian, M. Gu, Microstructure and mechanical properties of boron carbide thin films, Mater. Lett. 57 (2002) 899

8. S. Ulrich, H. Ehrhardt, J. Schwan, R. Samlenski, R. Brenn, Subplantation effect in magnetron sputtered superhard boron carbide thin films, Diam. Relat. Mater. 7 (1998) 835 
9. P.D. Cuong, H. Ahn, E. Yoon, K. Shin, Effects of relative humidity on tribological properties of boron carbide coating against steel, Surf. Coat. Techn. 201 (2006) 42304235

10. J. Eichstädt, G.R.B.E. Römer, A.J. Huis in't Veld, Towards Friction Control using laserinduced periodic Surface Structures, Physics Procedia 12 (2011) 7-15

11. J. Bonse, R. Koter, M. Hartelt, D. Spaltmann, S. Pentzien, S. Höhm, A. Rosenfeld, J. Krüger, Tribological performance of femtosecond laser-induced periodic surface structures on titanium and a high toughness bearing steel, Appl. Surf. Sci. (2014), http://dx.doi.org/10.1016/j.apsusc.2014.08.111.

12. N. Yasumaru, K. Miyazaki, J. Kiuchi, Control of tribological properties of diamond-like carbon films with femtosecond-laser-induced nanostructuring, Appl. Surf. Sci. 254 (2008) 2364-2368.

13. C.S. Lim, M.H. Hong, Y. Lin, G.X. Chen, A. Senthil Kumar, M. Rahman, L.S. Tan, J.Y.H. Fuh, G.C. Lim, Sub-micron surface patterning by laser irradiation through microlens arrays, J. Mater. Process. Tech., 192-193 (2007) 328-333

14. M. Mäder, T. Höche, J.W. Gerlach, R. Böhme, K. Zimmer, B. Rauschenbach, Large area metal dot matrices made by diffraction mask projection laser ablation, Phys. status solidi - r 2 (2008) 34

15. M. Mäder, K. Zimmer, R. Böhme, T. Höche, J.W. Gerlach, B. Rauschenbach, NanoPatterning by Diffraction Mask-Projection Laser Ablation, Journal of Laser MicroNanoengineering 3 (2008) 9

16. B. N. Chichkov, C. Momma, S. Nolte, F. von Alvensleben, A. Tünnermann, Femtosecond, picosecond and nanosecond laser ablation of solids. Appl. Phys. AMater., 63 (1996) 109-115.

17. V. Oliveira, S. Ausset and R. Vilar, Surface micro/nanostructuring of titanium under stationary and non-stationary femtosecond laser irradiation. Appl. Surf. Sci., 2009. 255(17): p. 7556-7560.

18. S. Alves, V. Oliveira and R. Vilar, Femtosecond laser ablation of dentin. J. Phys. D Appl. Phys., 45 (2012) 245401.

19. V. Oliveira, R. Vilar, R. Serra, J.C. Oliveira, N.I. Polushkin and O. Conde, Sub-micron structuring of silicon using femtosecond laser interferometry. Opt. Laser Technol., 54 (2013) 428-431.

20. R. Vilar, S.P. Sharma, A. Almeida, L.T. Cangueiro and V. Oliveira, Surface morphology and phase transformations of femtosecond laser-processed sapphire. Appl. Surf. Sci., 288 (2014) 313-323.

21. M. Pfeiffer, A. Engel, H. Gruettner, K. Guenther, F. Marquardt, G. Reisse, S.

Weissmantel, Ripple formation in various metals and super-hard tetrahedral amorphous carbon films in consequence of femtosecond laser irradiation. Appl. Phys. A - Mater., 110 (2013) 655-659. 
22. R. Le Harzic, D. Dörr, D. Sauer, M. Neumeier, M. Epple, H. Zimmermann and F. Stracke, Large-area, uniform, high-spatial-frequency ripples generated on silicon using a nanojoule-femtosecond laser at high repetition rate. Opt. Lett., 36 (2011) 229-231.

23. A.R. de la Cruz, R. Lahoz, J. Siegel, G.F. de la Fuente, J. Solis, High speed inscription of uniform, large-area laser-induced periodic surface structures in $\mathrm{Cr}$ films using a high repetition rate fs laser. Opt. Lett., 39 (2014) 2491-2494.

24. A. Cunha, A.P. Serro, V. Oliveira, A. Almeida, R. Vilar, M.-C. Durrieu, Wetting behaviour of femtosecond laser textured Ti-6Al-4V surfaces. Appl. Surf. Sci., 265 (2013) 688-696.

25. D. R. Tallant, T. L. Aselage, A. N. Campbell and D. Emin, Boron carbide structure by Raman spectroscopy, Phys. Rev. B 40 (1989) 5649-5656.

26. R. Lazzari, N. Vast, J. M. Besson, S. Baroni and A. Dal Corso, Atomic Structure and Vibrational Properties of Icosahedral B4C Boron Carbide, Phys. Rev. Lett. 83 (1999) 3230-3233.

27. K. Shirai and S. Emura, Lattice Vibrations of Boron Carbide, J. Solid State Chem. 133 (1997) 93-96.

28. B. Nunes, A.P. Serro, V. Oliveira, M.F. Montemor, E. Alves, B. Saramago and R. Colaço, Ageing effects on the wettability behavior of laser textured silicon. Appl. Surf. Sci., 257 (2011) 2604-2609.

29. M.-L. Wu, J.D. Kiely, T. Klemmer, Y.-T. Hsia and K. Howard, Process-property relationship of boron carbide thin films by magnetron sputtering. Thin Solid Films, 449 (2004) 120-124.

30. V. Kulikovsky, V. Vorlicek, R. Ctvrtlik, P. Bohac, L. Jastrabik, H. Lapsanska, Effect of air annealing on mechanical properties and structure of amorphous $\mathrm{B}_{4} \mathrm{C}$ films. Surf. Coat. Techn. 205 (2011) 4052-4057.

31. J. Bonse, J. Krüger, S. Höhm and A. Rosenfeld, Femtosecond laser-induced periodic surface structures. J. Laser Appl., 24 (2012) 042006.

32. U. Chakravarty, R.A. Ganeev, P.A. Naik, J.A. Chakera, M. Babu and P.D. Gupta, Nanoripple formation on different band-gap semiconductor surfaces using femtosecond pulses. J. Appl. Phys., 109 (2011) 084347.

33. V. Domnich, S. Reynaud, R.A. Haber and M. Chhowalla, Boron Carbide: Structure, Properties, and Stability under Stress. J. Am. Ceram. Soc., 94 (2011) 3605-3628.

34. J.E. Sipe, J.F. Young, J.S. Preston, and H.M. van Driel, Laser-induced periodic surface structure. I. Theory, Phys. Rev. B 27 (1983) 1141-1154. 


\section{Figure Captions}

Fig. 1: SEM micrographs of the as-deposited B-C thin films obtained at different subtract temperatures: (a) $200^{\circ} \mathrm{C}$; (b) $800^{\circ} \mathrm{C}$; (c) and (d) $1000^{\circ} \mathrm{C}$.

Fig. 2: Micro-Raman spectra of the as-deposited B-C thin films.

Fig. 3: SEM micrographs of the surface morphology of B-C films deposited at $200^{\circ} \mathrm{C}$ after irradiation with pulse energies of (a) 65 , (b) and (c) 72 , and (d) $78 \mu \mathrm{J}$.

Fig. 4: 3D topographical images and 2D profiles of the surface of B-C films deposited at 200 ${ }^{\circ} \mathrm{C}$ treated with pulses energy of (a) 65 ; and (b) $72 \mu \mathrm{J}$.

Fig. 5: Raman spectra of the films deposited at $200{ }^{\circ} \mathrm{C}$, before and after femtosecond laser processing with pulse energies of (a) 65 and (b) $72 \mu \mathrm{J}$.

Fig. 6: SEM micrographs of the surface morphology of B-C films deposited at $800{ }^{\circ} \mathrm{C}$ after irradiation with pulse energies of (a) 65 , (b) 72 , (c) 78 , and (d) $85 \mu \mathrm{J}$.

Fig. 7: 3D topographical images, 2D profiles and amplitude spectrum of the surface of B-C films deposited at $800{ }^{\circ} \mathrm{C}$ treated with pulses energies of (a) 72 and (b) $78 \mu \mathrm{J}$.

Fig. 8: Raman spectra of the films deposited at $800{ }^{\circ} \mathrm{C}$ after femtosecond laser surface processing with pulses energies of (a) 72 and (b) $78 \mu \mathrm{J}$.

Fig. 9: SEM micrographs of the surface morphology of B-C films deposited at $1000{ }^{\circ} \mathrm{C}$ after irradiation with pulse energies of (a) 50 , (b) 65 , (c) $72 \mu \mathrm{J}$, (d) $80 \mu \mathrm{J}$.

Fig. 10: 3D topographical images and 2D profiles of the surface of $B-C$ films deposited at $1000{ }^{\circ} \mathrm{C}$ treated with pulse energies of (a) 65 and (b) $72 \mu \mathrm{J}$.

Fig. 11: Micro Raman spectra for B-C films deposited at $1000^{\circ} \mathrm{C}$ and processed using different femtosecond laser pulses energy. 


\section{Table Captions}

Table 1: Spatial period of the LIPSS 


\begin{tabular}{ccc}
\hline $\begin{array}{c}\text { Film deposition } \\
\text { temperature }\left({ }^{\circ} \mathbf{C}\right)\end{array}$ & $\begin{array}{c}\text { Laser pulse } \\
\text { energy }(\mu \mathrm{J})\end{array}$ & $\begin{array}{c}\text { LIPSS spatial } \\
\text { period }(\mathbf{n m})\end{array}$ \\
\hline 200 & 72 & 180 \\
\hline \multirow{2}{*}{300} & 72 & 185 \\
& 78 & 225 \\
\hline \multirow{2}{*}{1000} & 50 & 140 \\
& 65 & 150 \\
& 72 & 200 \\
\hline \hline
\end{tabular}




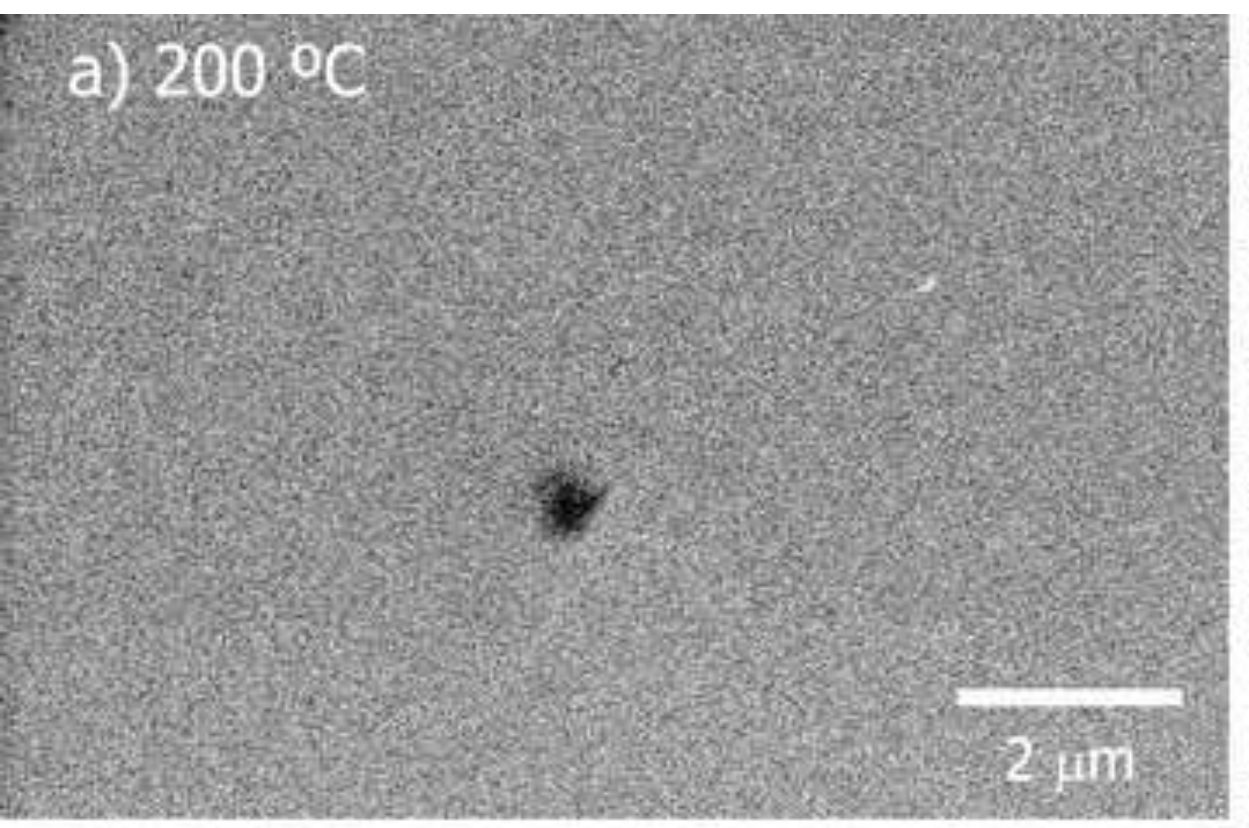

c) $10000 \mathrm{C}$
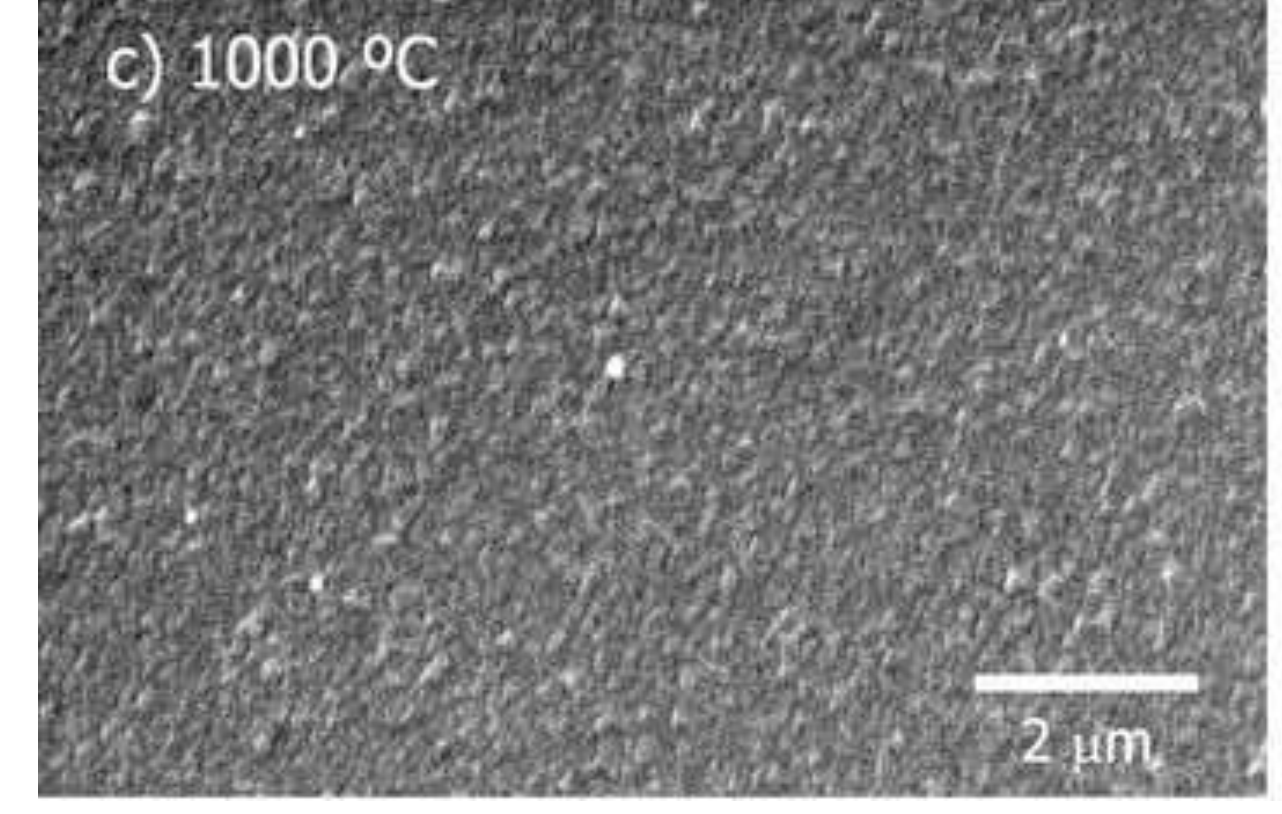

b) $800^{\circ} \mathrm{C}$
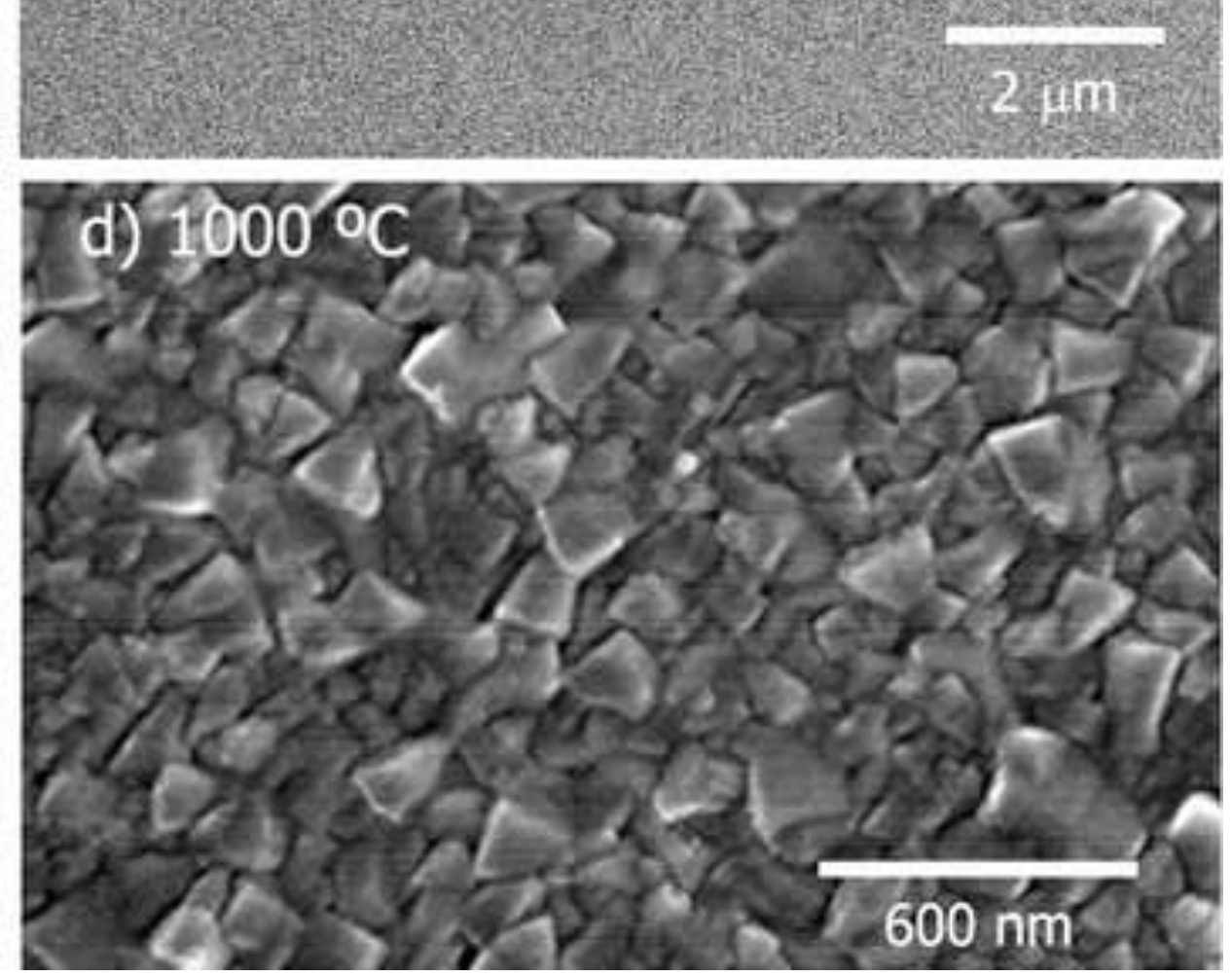

Page 17 of 27 


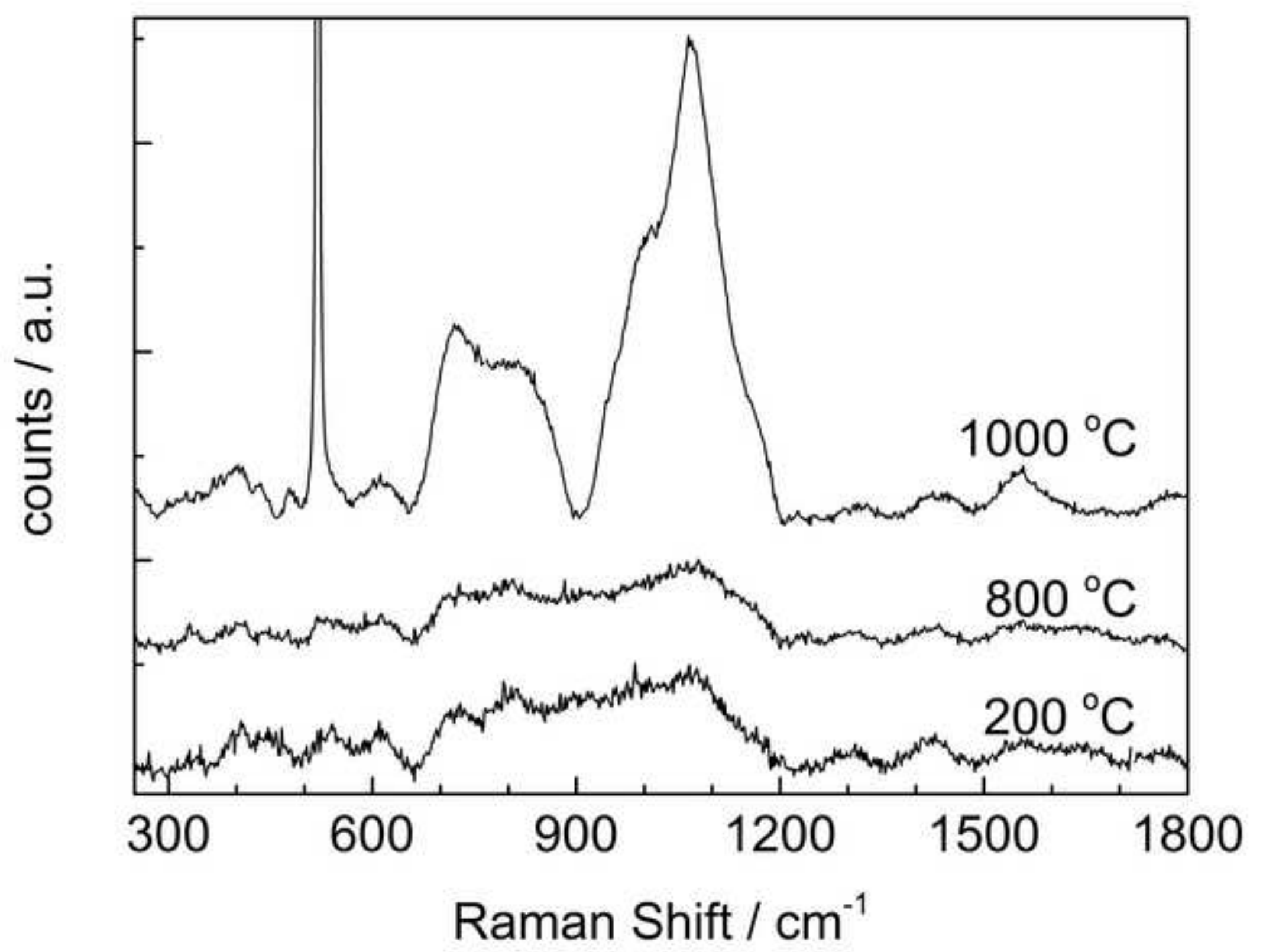

rage 18 or 21 
a) $0.65 \mu \mathrm{J}$

Б) $0.72 \mu \mathrm{J}$

\section{$2 \mu \mathrm{m}$}

c) $0.72 \mu \mathrm{J}$

d) $0.78 \mu \mathrm{J}$
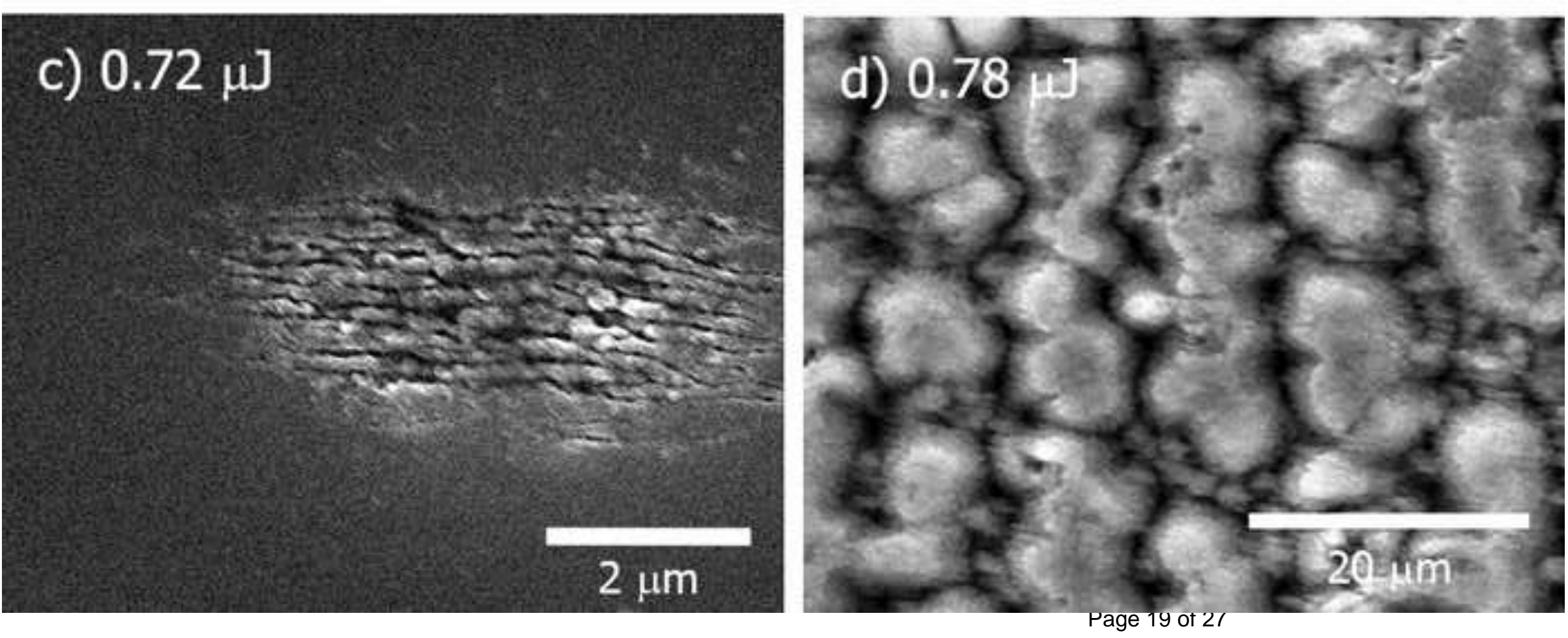

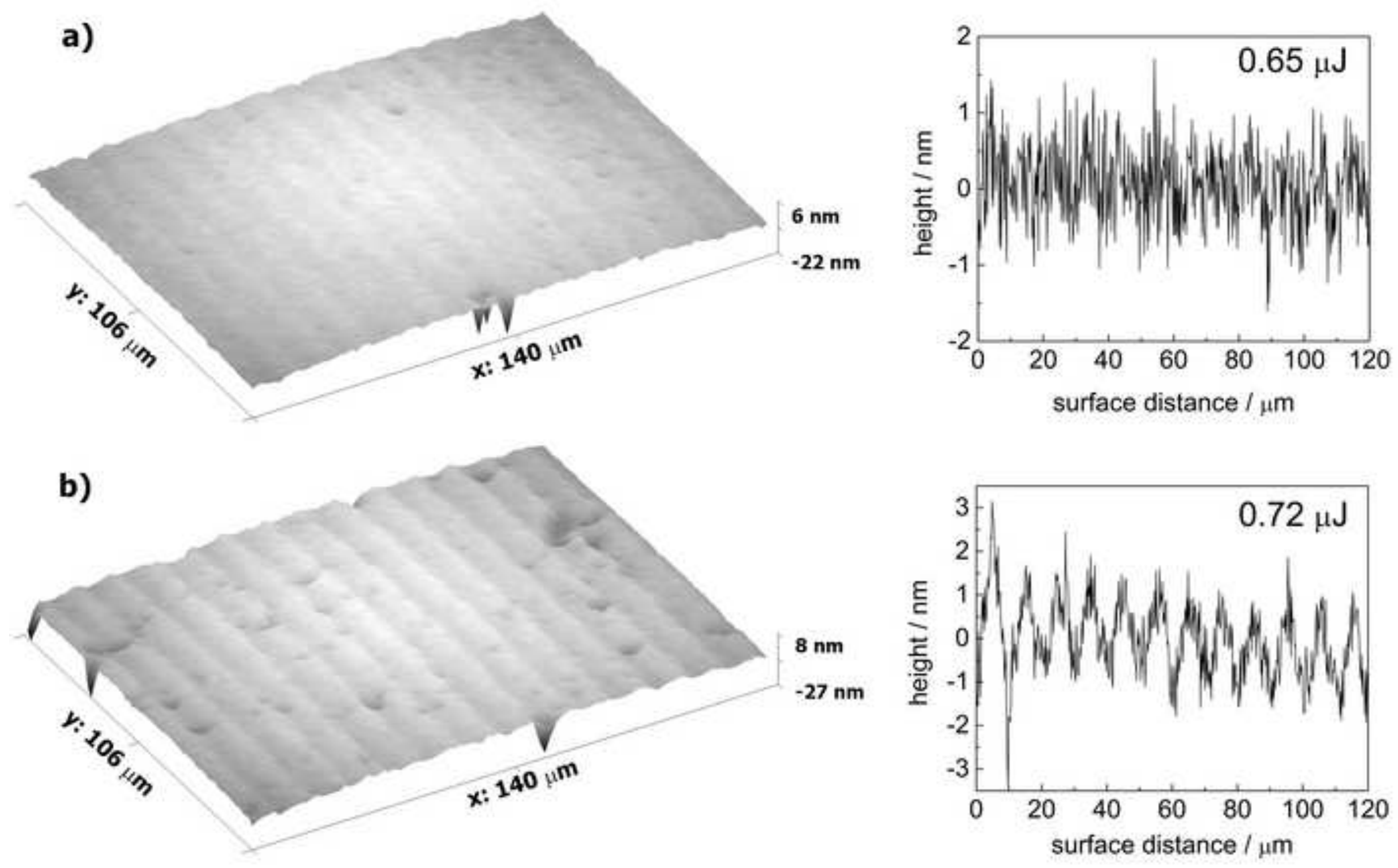


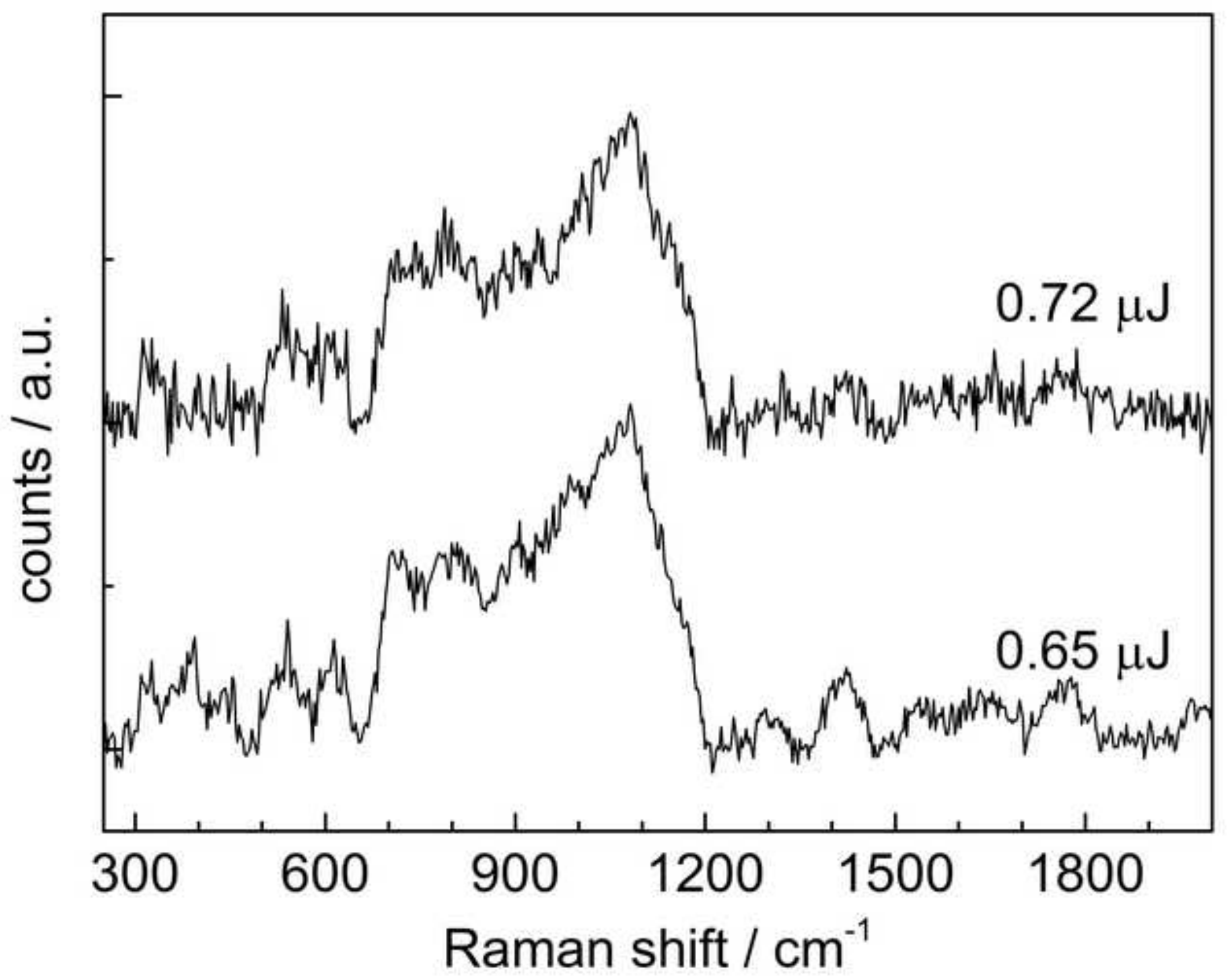

rage 21 or 21 
a) $0.65 \mu \mathrm{J}$
b) $0.72 \mu \mathrm{J}$
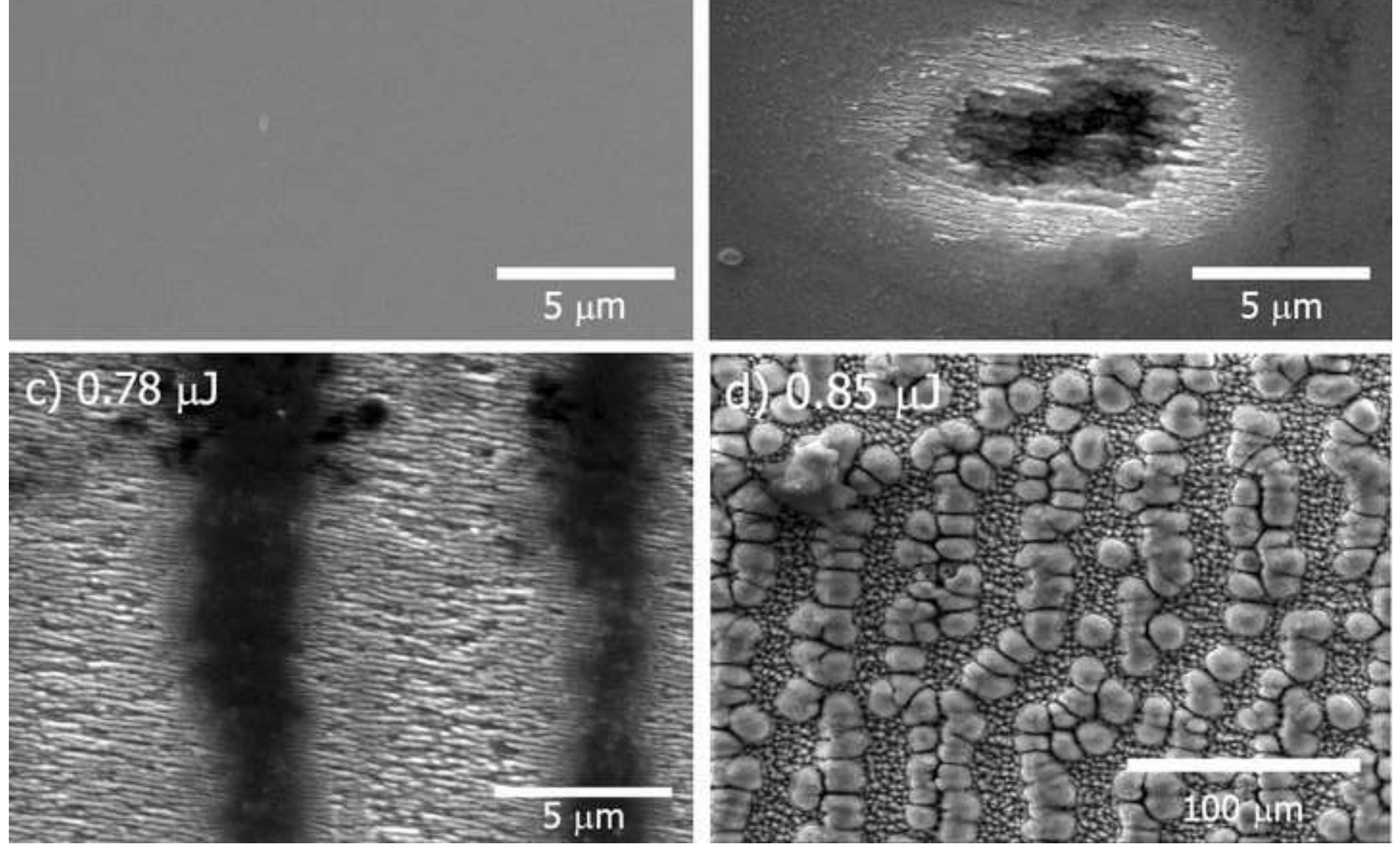

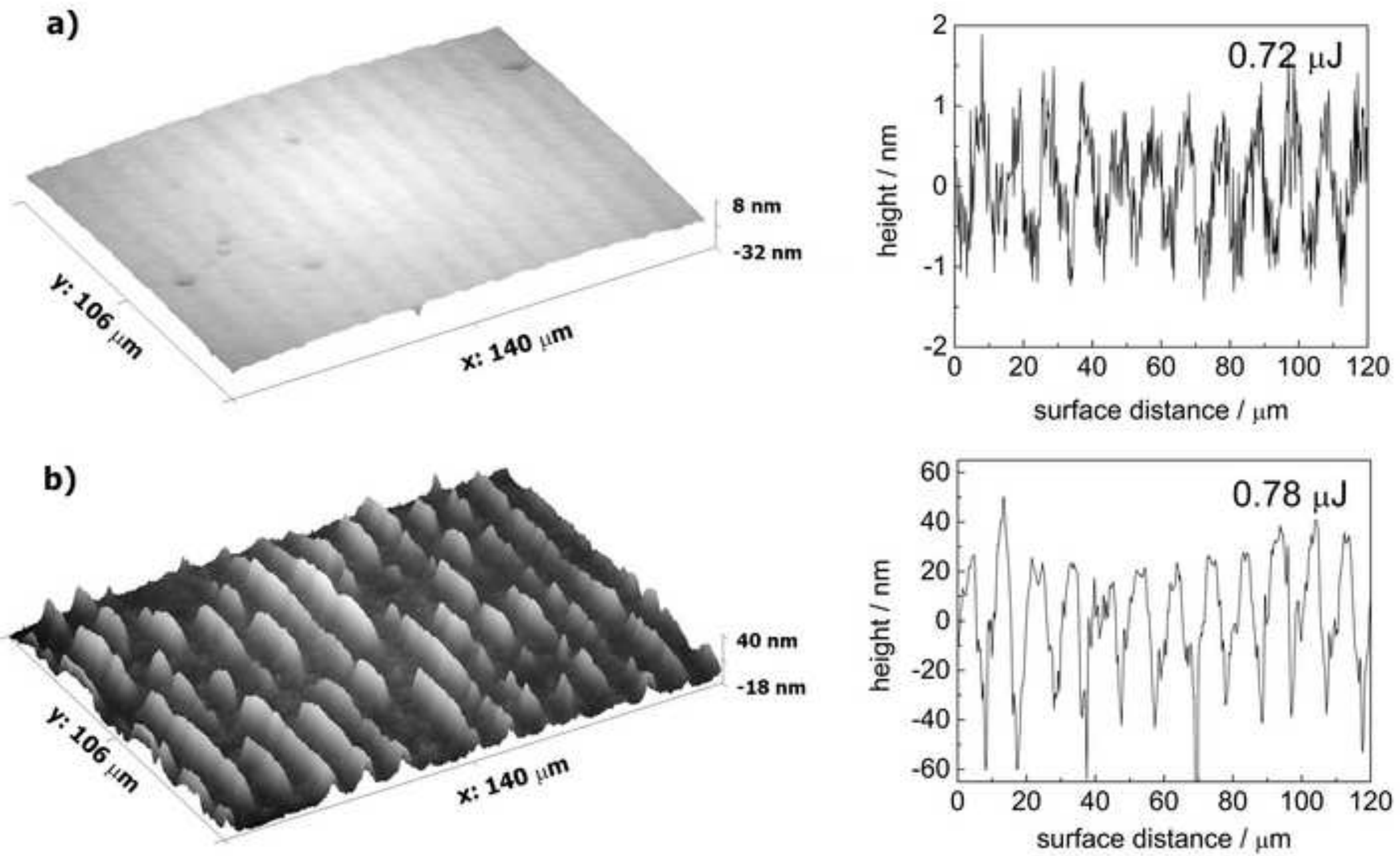


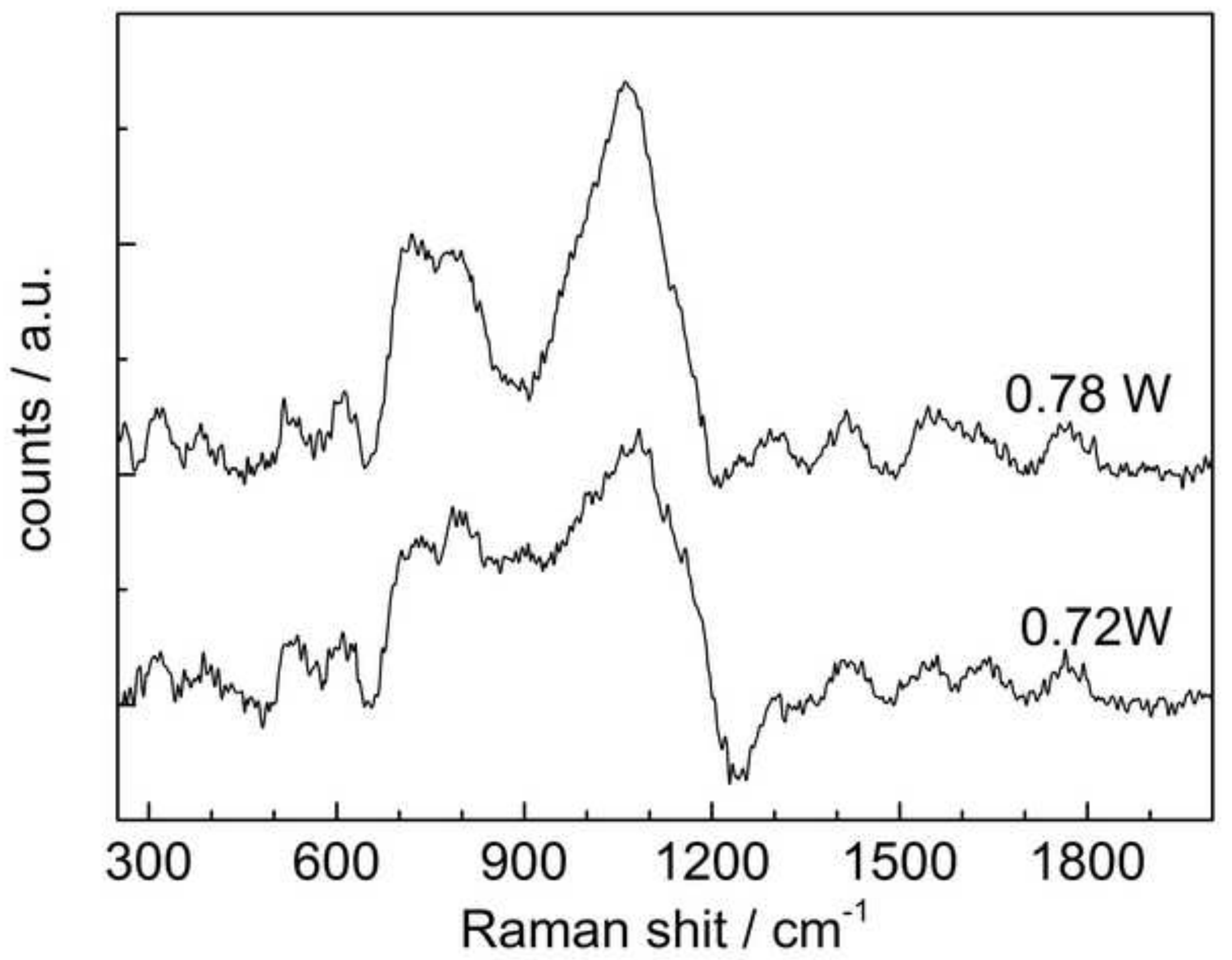

rage 24 or 21 
a) $0.50 \mathrm{HS}$
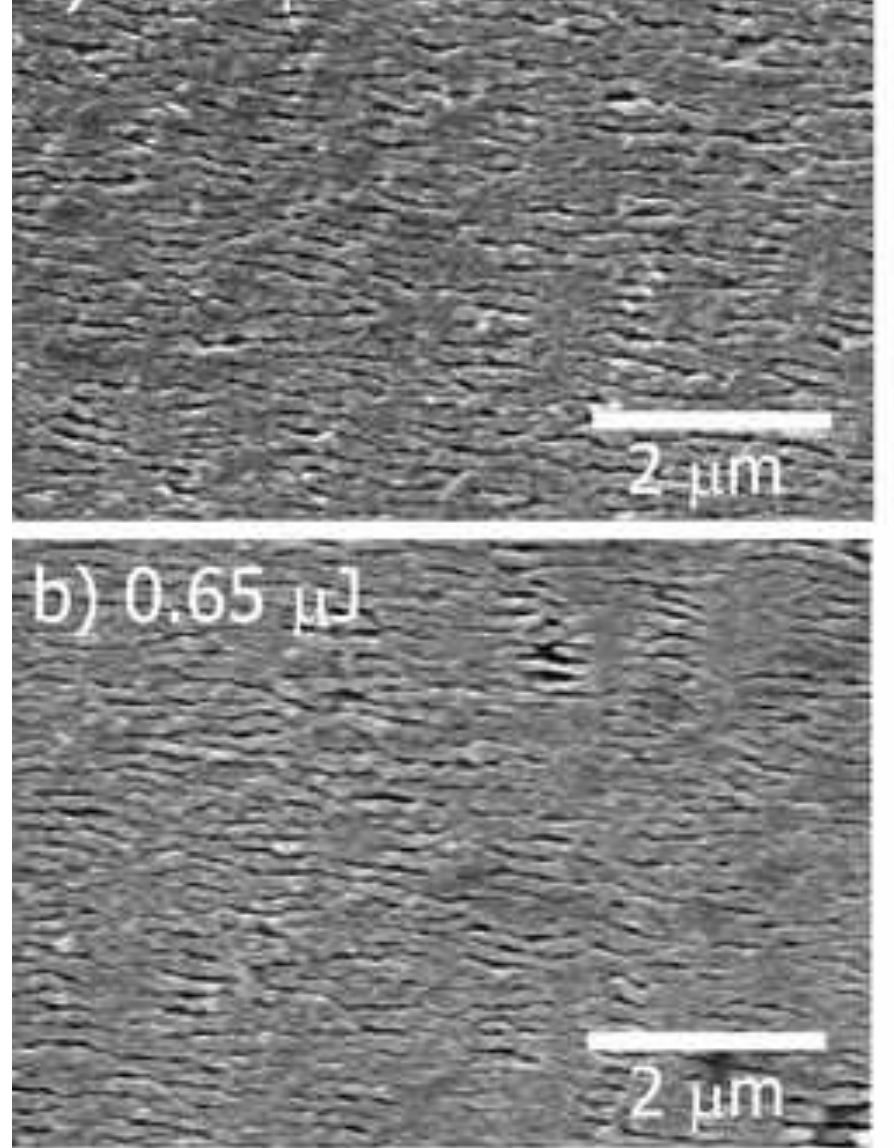
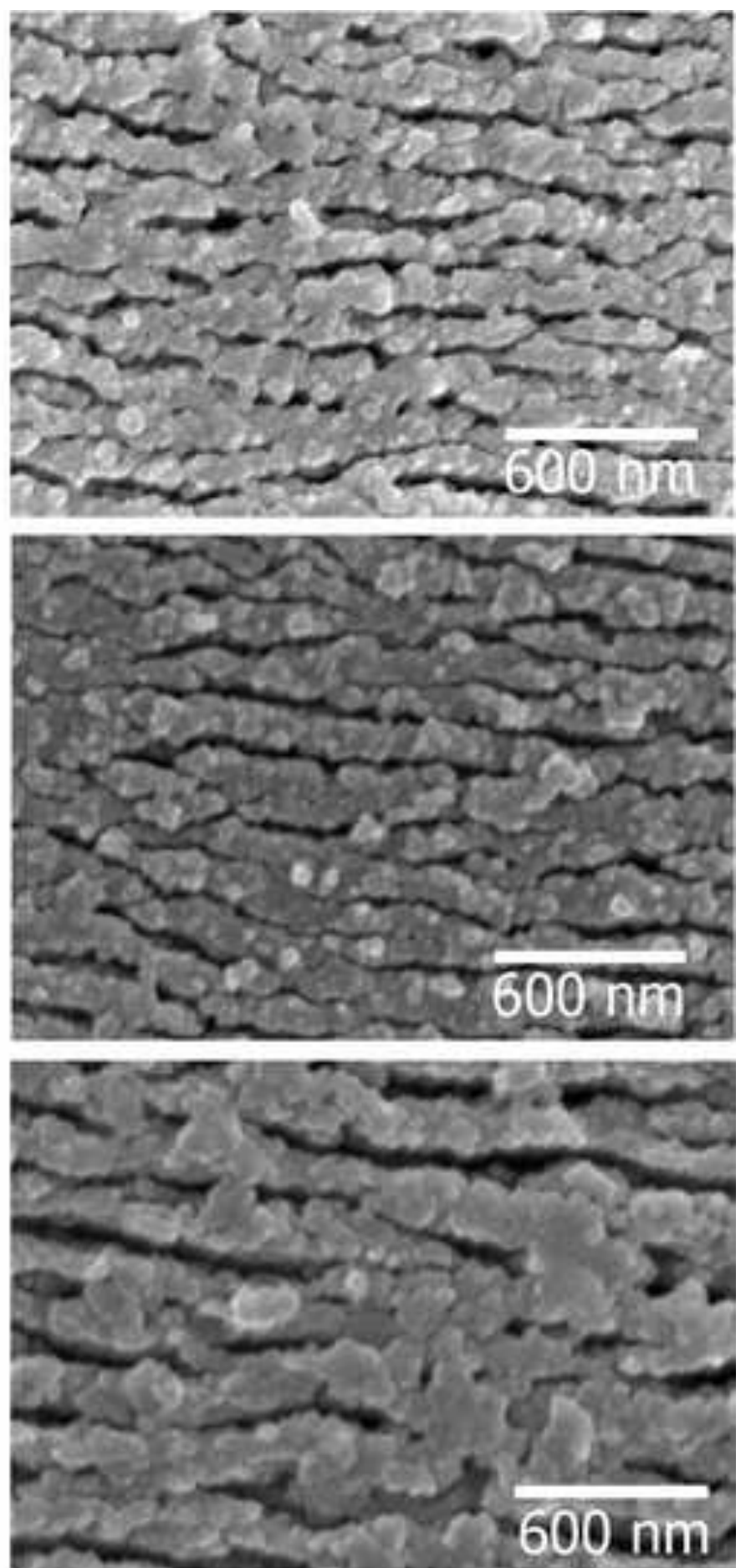
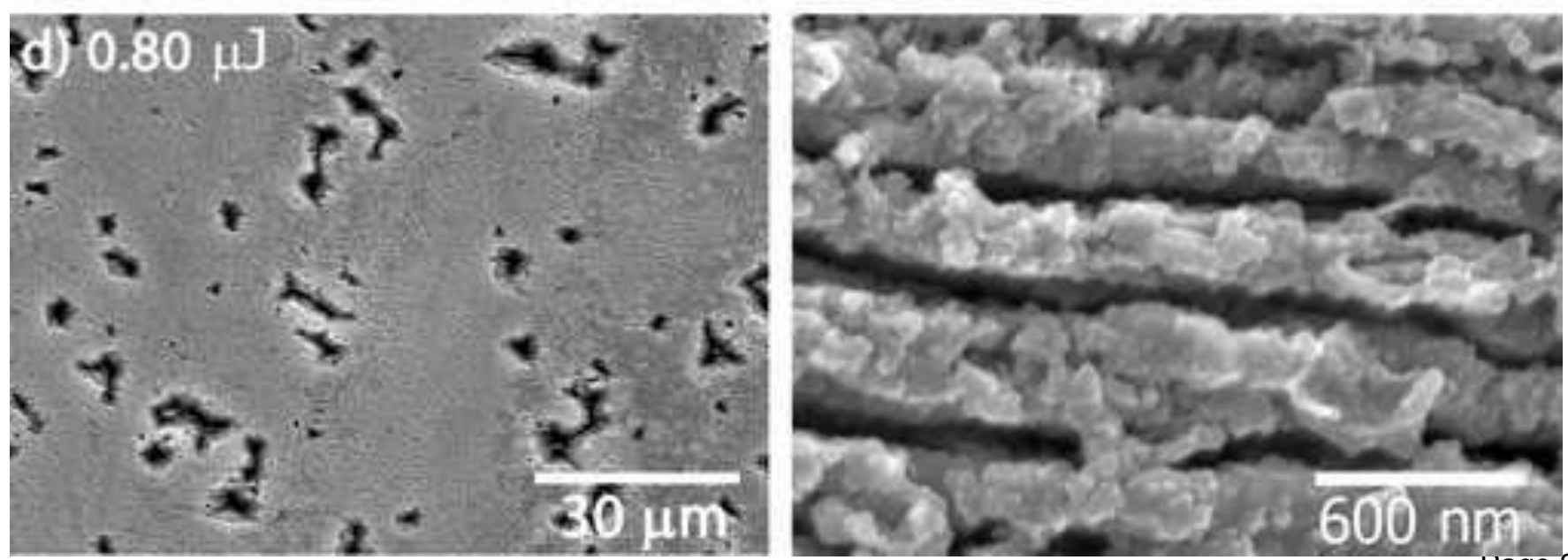

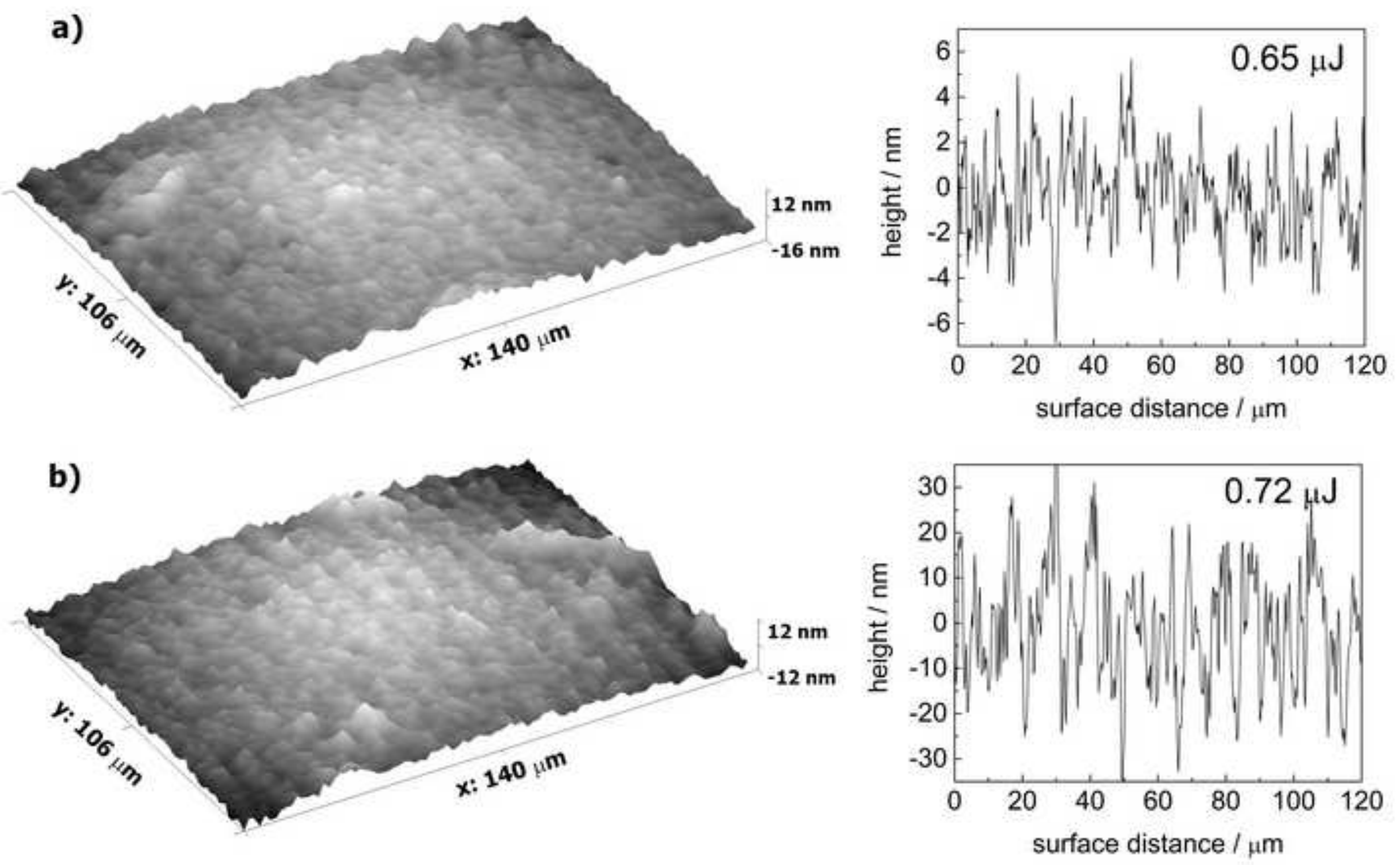


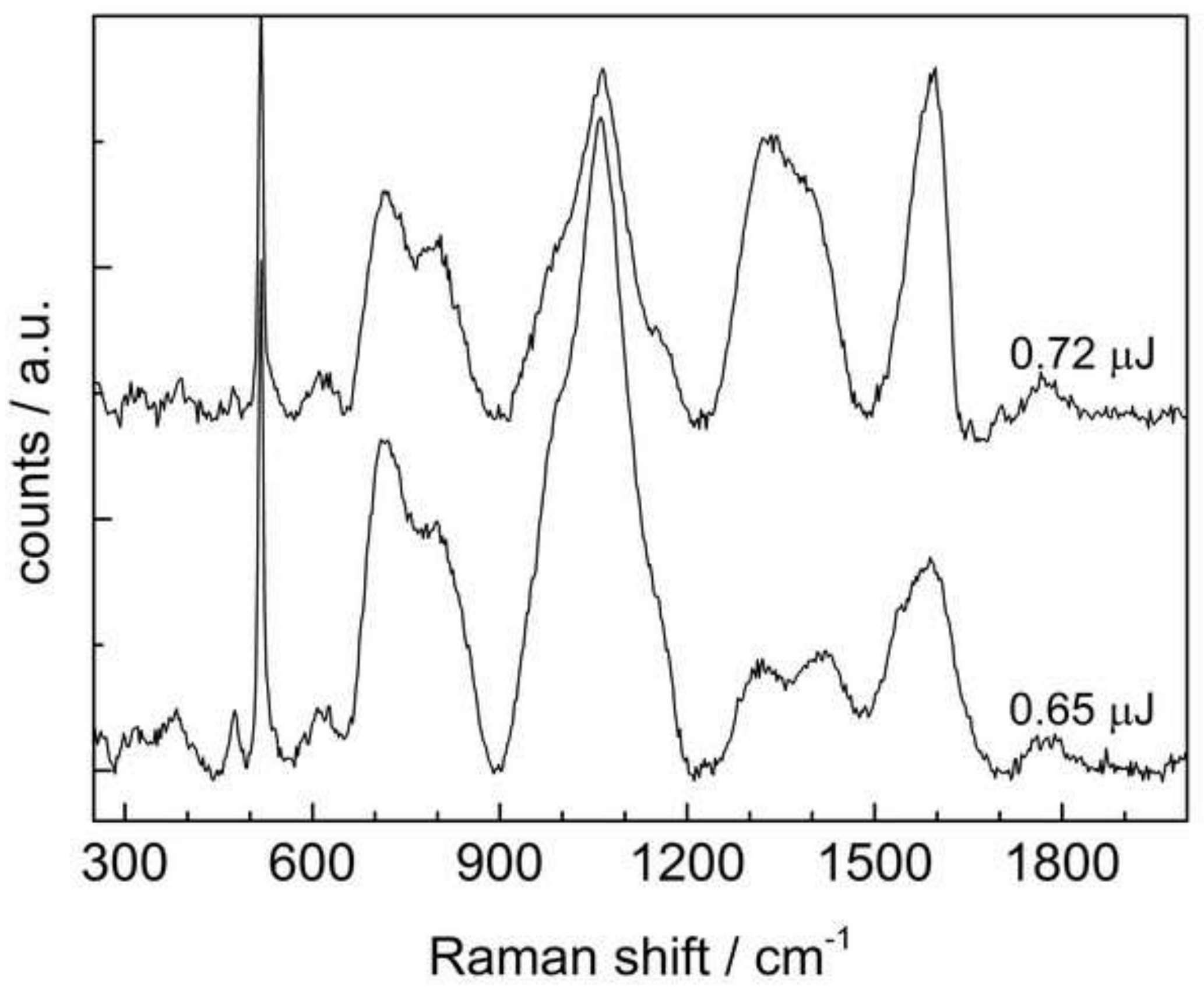

rage 21 or 21 